\title{
Análisis cualitativo y tendencias de los participantes (profesionales y académicos) en eventos realizados en España sobre periodismo digital y redes sociales
}

\author{
Elvira CALVO GUTIÉRREZ \\ Universidad Complutense de Madrid \\ ecalvogu@ccinf.ucm.es
}

Recibido: 16 de julio de 2015

Aceptado: 18 de septiembre de 2015

\begin{abstract}
Resumen
El desarrollo de Internet y de la tecnología digital ha producido un vuelco en la profesión periodística. Desde que se iniciara el siglo XXI, esos cambios son objeto de foros y debates. Las tecnologías han cambiado la forma de hacer periodismo y la convergencia de medios es una consecuencia. Los cambios se han producido en todos los niveles del proceso de producción informativa; en la toma de decisiones, en las redacciones y entre las audiencias. En este artículo se analiza la calidad de los congresos, encuentros, foros y seminarios que se organizan en España en torno al periodismo digital y las redes sociales con especial detalle en dos aspectos: las conclusiones y el perfil de los ponentes, tanto en su vertiente profesional como académica.
\end{abstract}

Palabras clave: Periodismo digital, congresos, profesionales, académicos.

\section{Qualitative analysis and trends of participants (professional and academic) in Spanish events about digital journalism and social networks}

\begin{abstract}
Internet development and digital technology has produced a shift in journalism. Since the twenty-first century began, these changes are the subject of forums and debates. The technologies have changed the way journalism and media convergence is a consequence. Changes have occurred at all levels of the process of news production; in decision-making, in newsrooms and among audiences. This article is a analysis about the quality of conferences, meetings, forums and seminars organized in Spain around digital journalism and social media in particular detail in conclussions and the profile of the speakers, professional and academic side.
\end{abstract}

Keywords: Digital journalism, conferences, forums, professionals, academics.

\section{Referencia normalizada}

CALVO GUTIÉRREZ, Elvira (2015): “Análisis cualitativo y tendencias de los participantes (profesionales y académicos) en eventos realizados en España sobre periodismo digital y redes sociales". Estudios sobre el Mensaje Periodístico. Núm. especial diciembre, págs.: 35-48. Madrid, Servicio de Publicaciones de la Universidad Complutense.

Sumario: 1. Introducción. 2. Fuentes y metodología. 3. Principales congresos; 3.1. Congreso de Periodismo Digital de Huesca; 3.2. Otros congresos. 4. El periodismo digital en el ámbito académico. 5. Conclusiones. 6. Referencias bibliográficas.

\section{Introducción}

El desarrollo de Internet y de la tecnología digital ha producido un vuelco en la profesión periodística. Desde que se iniciara el siglo XXI, esos cambios son objeto de foros y debates que han visto su reflejo en la primera bibliografía científica sobre la disciplina del periodismo en la era de la información digital, conocido ya como ciberperiodismo. Las tecnologías han cambiado la forma de hacer periodismo y la convergencia de medios es una consecuencia, con todo lo que ello supone. Los cambios 
se han producido en todos los niveles del proceso de producción informativa: se multiplican los medios de comunicación (más cantidad, menos calidad); se valora la información instantánea, al minuto, más que la profundidad o el análisis; las redacciones se unifican para aprovechar recursos y el periodista se convierte en el hombre orquesta, tan temido como anunciado; los altos directivos que dirigen los medios, asisten atónitos a una nueva era en la que cambia lo más importante para ellos: la financiación a través de la publicidad; y las audiencias, no solo dejan de ser fieles a su medio, sino que se convierten en usuarios de información, lo que les permite intervenir y comentar el producto informativo, e incluso, producirlo, distribuirlo o compartirlo. Aparecen nuevos conceptos (periodismo digital, periodismo ciudadano, "prosumer", cibermedio) relacionados, o consecuencia, de Internet. Nunca hubo tantos medios de comunicación como en la actualidad y, paradójicamente, nunca hubo tantos periodistas.... en paro.

Las causas y las consecuencias no dejan de analizarse en congresos y foros organizados a lo largo y ancho del país. Unos en torno al mundo académico; otros en torno a las asociaciones de prensa. Algunos ponentes se atreven a augurar el futuro lejano y otros se limitan a recoger las tendencias más exitosas pero lo cierto es que todos los foros concluyen que lo que ha cambiado no es el periodismo, sino el modelo de negocio: la forma de hacer periodismo sigue siendo la misma. El olfato periodístico, la forma de contar las cosas, las fuentes, ... siguen siendo las mismas de siempre; ha cambiado el modelo de negocio, sí, es cierto, y solo tenemos que remontarnos a finales de los años 90 cuando todos los diarios corrieron a subirse a la red porque era la moda, sin pensar en cómo cobrar por ello. Han pasado 15 años desde entonces y los lectores, hoy usuarios, ya no conciben pagar por informarse. Los diarios, pues, están pagando caro esa precipitación por subirse a las nuevas tecnologías que nos ofrecía el siglo XXI sin pensar en las consecuencias. Si nos detenemos en los otros dos medios de comunicación tradicionales, la radio y la televisión, resulta que también son gratuitos. A todo ello hay que añadir otro factor determinante: si acceder a la información es un derecho constitucional, ¿es ilegal cobrar por ella? ¿Deben los medios de comunicación financiar sus espacios informativos con los ingresos que perciban por realizar otro tipo de contenidos?

Quizá resulte que la información debe ser un bien general gratuito. Pero ¿cómo es posible que durante décadas las empresas informativas llegaran a ganar tanto dinero y tener tanto poder? ¿Qué ha fallado? ¿El modelo de negocio? ¿la financiación? Valga un ejemplo: en apenas unos años, el banner, la milagrosa herramienta publicitaria online se ha demostrado inútil. Los publicitarios tradicionales colocaron el clásico faldón de prensa en la corona de una página web pensando que atraería millones de clicks. Pero lo cierto es que Internet se desarrolló deprisa, las páginas web se triplicaron y el número de usuarios creció tanto que los banner dejaron de ser atrayentes y no hubo tiempo para que se formaran nuevos publicistas capaces de entender el nuevo lenguaje. Sí, el mundo de la publicidad ha dado un vuelco de ciento ochenta grados. Pero no es la única causa. También han cambiado los gustos de las audiencias, la forma de consumir información, la preferencia de unos contenidos sobre otros, la distribución, etc. 


\section{Fuentes y metodología}

Todas estas reflexiones anteriores se tratan, desde los ámbitos académico y profesional, en numerosos congresos, seminarios y foros sobre el futuro del periodismo, el periodismo digital y las redes sociales que se organizan en España. Este artículo pretende resumir un trabajo más amplio que se enmarca en el proyecto de investigación "Cybermedios II" (Ref. CSO2011-25235) centrado en el análisis de los principales congresos atendiendo a tres premisas principales: el ente organizador; el número de ediciones; y el número de participantes que logra convocar. Aunque los congresos objeto de análisis son cuatro, por motivos de espacio, el presente trabajo pone el foco de atención en uno de ellos, el Congreso de Periodismo Digital de Huesca, por ser el pionero, aunque con importantes referencias a los otros tres: Congreso de Ciberperiodismo y Web 2.0 de Bilbao, Congreso de Periodismo y Comunicación Digital de Andalucía y Congreso de Periodismo en Red de Madrid.

En base a la investigación realizada, la hipótesis -tanto del trabajo amplio desarrollado para el proyecto de investigación Cybermedios II como del presente artículo-, se basa en demostar que lo que hace quince años se llamó "periodismo digital" es actualmente el periodismo del siglo XXI. Si hace más de dos décadas se asociaba con las nuevas tecnologías de la información y la comunicación, la sociedad de la información y el desarrollo de Internet, hoy todo el periodismo es digital. Ya no tiene sentido, pues, hablar de periodismo digital como se puede comprobar en los actuales programas de los congresos analizados.

El objetivo es plasmar la evolución que han sufrido los propios congresos -en cuanto a contenidos, ponentes, preocupaciones profesionales y conclusiones- a lo largo de más de quince años que llevan organizándose en nuestro país y, por ende, el desarrollo que ha tenido el concepto "periodismo digital".

Las fuentes a las que se ha recurrido para el trabajo de investigación son tres principalmente: por un lado, se ha consultado la extensa bibliografía relacionada con las nuevas formas de periodismo en el siglo XXI; por otro, los sites de los propios congresos que albergan programas, resúmenes, conclusiones e histórico; y, por último, algunos de los organizadores y ponentes que amablemente han respondido, vía email, a un cuestionario relativo a la evolución de los respectivos congresos, el perfil profesional, los contenidos y ponencias, los temas estrella, las preocupaciones laborales del momento, las soluciones apuntadas en cada edición, etc. De las respuestas obtenidas, un total de 12 (6 de Huesca, 2 de Bilbao, 3 de Madrid y 1 de Andalucía) se ha elaborado un informe del que se han extraído las principales conclusiones de este trabajo.

La metodología seguida para la elaboración de este trabajo se ha basado en el análisis exhaustivo de los diferentes congresos atendiendo a sus programas y contenidos anuales, al perfil profesional o académico de sus ponentes y a las conclusiones; también has sido fundamentales las respuestas obtenidas a través del cuestionario enviado a los organizadores de los congresos y a alguno de los ponentes que acuden regularmente a ellos.

El volumen de información obtenido ha sido tan abundante que es imposible recogerlo en este artículo como ya se ha señalado anteriormente. Por ese motivo, y tras un importante esfuerzo de síntesis, se desarrolla más extensamente el Congreso de 
Periodismo Digital de Huesca -por ser el pionero y el que más ediciones ha celebradoen detrimento de los otros tres congresos analizados, aunque sí se plasmen, a título informativo, algunos aspectos de los mismos. Tampoco se recogen, por ejemplo, los programas ni los currículas de los ponentes más asiduos que,en el trabajo de campo, sirvieron para dar una certera visión de los objetivos de la investigación.

En definitiva, se ha dado prioridad a la evolución de los contenidos tratados en cada edición de los congresos respectivos que, junto a las respuestas obtenidas a través de los cuestionarios, ha permitido llegar a unas conclusiones sobre los cambios y el futuro del periodismo. No es objeto de este trabajo calificar la calidad de uno u otro congreso pero sí extraer las conclusiones comunes de todos ellos lo que, sin duda, permite una radiografía de los asuntos comunes que se tratan y que explican, en cierta manera, los nuevos rumbos de la profesión periodística en asuntos tan dispares como el uso de las redes sociales o el intrusismo, por citar algunos.

\section{Principales congresos}

Como ya se ha señalado, los congresos -programas, organizadores, ponentes- objeto de análisis han sido elegidos atendiendo a tres premisas principales: el ente organizador; el número de ediciones; y el número de participantes. En la superficie de este tamiz, cuatro son los congresos internacionales que se celebran en España y que son objeto de un análisis cualitativo.

\subsection{Congreso de Periodismo Digital de Huesca}

El Congreso de Periodismo Digital de Huesca llegará este año a su 16 edición. Dirigido por Fernando García, director del Infocentro Digital de Huesca, la convocatoria suele reunir a más de 250 periodistas entre profesionales en activo, profesores y universitarios. Organizado por la Asociación de la Prensa de Aragón, en el encuentro se analizan y discuten las novedades que se producen en el ámbito del periodismo desde la perspectiva digital. Se caracteriza por lo protocolario de la inauguración con la asistencia de autoridades políticas regionales y locales, y porque los ponentes siempre proceden del ámbito profesional aunque el congreso abre siempre una ventana al ámbito universitario con la publicación de un libro que recoge las comunicaciones. Por lo tanto, en el escenario, profesionales del periodismo en activo y en la platea, profesores y alumnos que pagan la matrícula. Inaugurado siempre por directores de medios del más alto nivel (El Mundo, El País, $A B C$ ), el $80 \%$ de las respuestas indica que es el congreso menos académico pero el más exitoso ya que consigue reunir a más de 250 profesionales de ambos bandos, lo que sin duda constituye la clave de su éxito.

En su primera edición, se apuntaron algunos problemas que presentaba la red: la americanización y el peligro de la sobrecarga de información, dos asuntos que, analizados 15 años después, presentan toda su razón de ser. Las ponencias giraron en torno al periodista digital, los retos y oportunidades de las nuevas tecnologías, los medios de comunicación locales y regionales en el mundo digital, las nuevas alternativas del periodismo electrónico, experiencias de periodismo digital en España, la profesión de periodista digital, la influencia de Internet en la información económica y el periodismo electrónico. 
En la segunda edición, 2001, los temas estrella fueron los nuevos soportes, la evolución de los medios digitales y sobre todo el precio de los contenidos, pago o gratuito. Se anunció un periodo decisivo para aclarar la viabilidad de las diferentes opciones, dejando claro que en una primera fase podrían convivir sin excesivos problemas los modelos de pago y los gratuitos. La evolución posterior vendría determinada por la capacidad de fidelizar la audiencia que demuestren los modelos de pago y la capacidad de supervivencia de los modelos gratuitos en un medio que les resultará cada vez más hostil, con mayores exigencias de calidad y de contenidos diferenciados que elevarán los costes de producción en la oferta informativa. Cabía también una vía intermedia: recurrir a fórmulas alternativas de publicidad, todavía muy escasas en la red, al patrocinio, etc.

Se habló mucho del teletrabajo como una esperanza de mayor calidad de vida pero también se dejó claro que la red tenía una capacidad ilimitada de contenidos y que estaba abierta a todo el mundo lo que exigía unas constante actualización o lo que es lo mismo, aportaciones ilimitadas de trabajo lo que se aproxima, se dijo, a la esclavitud. Buena parte de los contenidos depende de colaboradores, en el mejor de los casos mal pagados. Además, se comentó que el mantenimiento de ediciones digitales exigía enormes y constantes inversiones que restan rentabilidad a otros aspectos empresariales; y que las relaciones entre los diferentes departamentos (por ejemplo, entre un periódico impreso y su edición digital) eran complicadas.

En 2002, se celebró la tercera edición del congreso, la que contó con mayor participación del ámbito universitario y periodistas extranjeros. Las conclusiones de este congreso marcaron un antes y un después. Se constató la preocupación de los profesionales ante las condiciones laborales del medio Internet y se hizo un llamamiento a las asociaciones y organizaciones de periodistas para que intensificaran sus esfuerzos en favor de la equiparación plena de los informadores de Internet con sus colegas de la prensa escrita, radio, televisión, agencias de prensa y cualquier otro de los medios convencionales, así como para la defensa de sus derechos profesionales.

Por otro lado, se subrayó la preocupación entre los periodistas por el desequilibrio en la relación entre las empresas editoras y los profesionales a la hora de negociar la defensa de los derechos de propiedad intelectual, un desequilibrio agudizado con la aparición de los medios digitales y se dudó de la eficacia de la actual legislación sobre propiedad intelectual para defender los derechos del periodista como autor. Además, se constataba que la irrupción de Internet en el mundo de la comunicación había difuminado la figura y el papel del periodista y había empeorado en muchos casos las condiciones laborales, fenómeno que se daba igualmente en Estados Unidos. Los ponentes más eufóricos en ediciones anteriores empezaron a hablar de la crisis en Internet. No había crisis en el número de usuarios ni de lectores de los medios digitales -que de hecho seguían creciendo-, sino en cuanto a la rentabilidad de las empresas que los editaban. El periodismo tradicional había entrado en crisis oficialmente.

En este III Congreso de Periodismo Digital de Huelga también se habló de la hiperespecialización de los medios de información gracias a Internet, lo que debería haber permitido realizar un periodismo de mayor calidad y rigor siempre que no se olvidara la vigencia de los criterios básicos que han caracterizado al buen hacer perio- 
dístico. Se decía que Internet ofrecía a los medios digitales una inmediatez comparable a la radio y la televisión, pero con la ventaja de contar con un mayor nivel de profundidad informativa. Todos coincidías en que la Red aportaba grandes posibilidades, en un entorno de globalización, para utilizar la información como elemento de movilización solidaria y de ayuda a poblaciones necesitadas.

En los dos congresos posteriores, 2004 y 2005, se fueron tratando todos los temas relacionados con el periodismo y la preocupación profesional por el nuevo entorno digital: prensa digital y corresponsales, periodismo ciudadano, los caminos de la publicidad digital, periodismo de divulgación tecnológica, periodismo narrativo en Internet, el periodismo del futuro (incluyendo el ámbito educativo) y las agencias de noticias en la red. Las incógnitas respecto al periodismo digital parecían cada vez más claras.

Inaugurados por directores de medios, ningún aspecto quedaba sin tratar: agencias, fotografía, marketing, televisiones, ediciones digitales de prensa tradicional, contenidos propios, o titularidad pública/privada, ésta última especialmente relevante al conseguir reunir, en 2005, a los directores de informativos de las principales cadenas de televisión: destacando la mesa en la que se debatió la titularidad de los medios y en la que intervinieron los directores de informativos de las principales televisiones: Antonio San José, CNN+; Fran Llorente, TVE (Director Informativos); Gloria Lomana, Antena 3; y Juan Pedro Valentín, Informativos Tele 5. Mientras que algunos ponentes parecían haber entrado en nómina (Guillermo Culell, Gumersindo Lafuente, Ignacion Escolar, José Cervera, etc.), llegaban auténticos gurús del periodismo que no hacían mas que aumentar el prestigio del congreso: Fernando González Urbaneja, entonces presidente de la APM o Victoria Prego, subdirectora de El Mundo.

Lo más destacado del VII Congreso, el de 2006, fue un coloquio sobre el periodismo del futuro que moderaron Forges y Pepa Fernández, en el que participaron estudiantes de periodismo de España y de Latinoamérica y una ponencia titulada "Diez años de periodismo en Internet" moderada por Fernando Jaúregui (ya director de Ociocritico.com) en la que debatieron Ramón Salaverría, profesor de la Universidad de Navarra, y Rosental Calmon Alves, responsable de la cátedra Knight de Periodismo Internacional y Director del Knight Center for the Americas de la Escuela de Periodismo de la Universidad de Texas en Austin, Estados Unidos.

En 2007, en el VIII Congreso, los temas se van ampliando a temas de salud, China, Ciudadanía 3.0, los medios locales, la expo de Zaragoza del año siguiente, el diseño y el nuevo papel de las revistas. Aparecen cada vez más ponentes internacionales (Jon Lee Anderson de The New Yorker, Samantha Appleton (Time) o Thomas Dworzak (fotógrafo de la agencia Magnum), sin olvidar la perspectiva local y regional.

En la edición de 2008 se empieza a hablar de emprendimiento pero también de la información política en Twitter, especialidad que cobra más relevancia al año siguiente. El congreso de 2009 se abre a políticos como Pedro Zerolo, Santiago Cervera, Cristina Cifuentes, Eva Almunia o Jordi Sevilla, Leire Pajín y Soraya Sáenz de Santamaría. Los ponentes clásicos han cambiado de puestos de trabajo: Gumersindo Lafuente ya no está en la edición digital de El Mundo, sino que ahora dirige un nuevo proyecto, Soitu.es. Mario Tascón ha pasado a ser editor de DixiREd y entrevista al ya habitual Jean Fraçois Fogel, periodista de Le Monde y asesor tecnológico. 
En el XI Congreso, celebrado en 2010, se habla de televisones en Internet y de la prensa digital en Italia. Los ponentes se reducen y los que venían desde Latinoamérica, esta vez no son invitados. La crisis está en su punto más álgido. Al año siguiente, 2011, el interés vuelve a subir. Inaugura el director de El País, Javier Moreno, tras su éxito con Wikileaks. Las redes sociales son ya las protagonistas absolutas del nuevo periodismo digital y se insiste en el emprendimiento como salida profesional a la crisis. El nuevo ecosistema del negocio de las noticias, generado por Internet, pero sobre todo por la gestión empresarial de los medios en los últimos años, hace que el periodismo se resienta hasta tal punto que está desapareciendo de los periódicos y revistas, decía Fernando García Mongay, director del congreso (Alzaga, 2011: 8).

El congreso de 2013 lo clausura Iñaki Gabilondo. Las conclusiones se centraron en dos puntos clave: por un lado, la necesidad de redefinir la profesión para elaborar información de calidad, contexto y profundidad; por otro, el emprendimiento y la creación de nuevos proyectos en nichos de mercado muy diversos.

La penúltima edición, la XV, se insiste en el emprendimiento, en cómo cobrar por la información, pero también en la radio digital y en las redes sociales sin olvidar los libros de estilo para medios digitales. Cambian los temas pero continúan los ponentes habituales: Gumersindo Lafuente, $\mathrm{M}^{\mathrm{a}}$ José Cantalapiedra, José Cervera, Pedro de Alzaga, Alfonso Armada, Guillermo Culell, etc.

\subsection{Otros congresos}

El Congreso de Ciberperiodismo y Web 2.0 de Bilbao está organizado por la Facultad de Ciencias Sociales y de la Comunicación a través del Departamento de Periodismo II de la Universidad del País Vasco, el Congreso de Ciberperiodismo y Web 2.0 celebrará este año 2015 su VII Edición. Su alma mater es el profesor Koldo Meso, un visionario que supo ver a tiempo no solo la relación entre el periodismo e Internet, tan obvia hoy en día, sino también la relación entre el periodismo y la web 2.0, en el que el verdadero protagonismo recae en las audiencias. El público se convierte en el editor de información; es él el que define cómo quiere ver la información; y está constituyendo comunidades en este proceso. La web 2.0 refuerza la idea del usuario como creador y no sólo como consumidor de medios. Aquellas personas que antes eran clientes de información se convierten paulatinamente en editores, y muchas de las aplicaciones asociadas con la web 2.0 pretenden ayudarles a organizar y publicar sus contenidos. La segunda cuestión es qué ocurrirá con el papel tradicional de las empresas de medios frente al progresivo aumento de la demanda de una nueva forma de información compartida y centrada en la comunidad.

El primer congreso (La revolución del periodismo ciudadano, 2009) recogía, pues, la gran rapidez con la que los medios de comunicación habían integrado la participación de las audiencias en sus sitios web. El abanico de herramientas y plataformas ofrecidas era muy amplio: valoración de informaciones, comentarios de noticias, envíos de contenidos, noticiosos en cualquier formato (texto, audio, vídeo, foto), encuestas, etc. Se decía entonces que, para la ciudadanía, estos mecanismos posibilitaba alzar la voz, dar a conocer sus opiniones y sus denuncias, mientras que para los medios, formaban parte de una estrategia dirigida a reforzar la marca, conseguir la fide- 
lidad de los lectores y generar tráfico, como un camino hacia la rentabilidad económica de los medios digitales. Durante los últimos años habíamos asistido a un incremento de espacios para los contenidos elaborados por las audiencias en los medios informativos y a una creciente integración de estos contenidos en los espacios reservados hasta ahora a los profesionales de la información. Esos cambios introducían nuevas pautas de comunicación y daban lugar a nuevas formas de expresión creativa, periodismo y participación. Todo ello había motivado el interés de los investigadores y de ahí la primera razón del congreso puesto que los estudios sobre la presencia de mecanismos de participación en los cibermedios y la actitud de los periodistas ante la participación eran abundantes frente a las escasas aportaciones académicas centradas en analizar la calidad de la participación de la audiencia, un aspecto crucial para evaluar la significación de los contenidos generados por los usuarios y su contribución al desarrollo de una esfera pública más enriquecedora.

Centrado siempre en las audiencias, no solo como consumidoras y productoras de contenidos, sino también como indicadores de calidad, el congreso intentaba explicar las estrategias que los medios de comunicación, considerados de referencia, estaban adoptando ante el hecho de que las audiencias demandaran más participación y, como consecuencia, estuvieran aceptando contenidos generados por los usuarios (User-Generated Content). El congreso exploraba las características, las herramientas, el impacto y las consecuencias para comprender, desde un punto de vista crítico, la naturaleza o el alcance de esos nuevos modelos. El objetivo era reunir a especialistas en el área para analizar y debatir cuestiones centradas en la práctica del Ciberperiodismo a la luz de las nuevas realidades empresariales, profesionales y de formación. Los desafíos y los cambios provocados por la convergencia y la multitextualidad, por el también llamado Periodismo ciudadano, por las innovaciones tecnológicas y las experiencias emprendedoras en esta área. Con los años, ha ido abandonando la idea del periodismo ciudadano por la construcción de nuevos modelos de comunicación (2010) o la transformación del espacio mediático (2012).

El congreso vasco suele invitar a algún periodista de medios (Montserrat Domínguez; Santiago Saiz de Apellániz de El Mundo; Andrea Vázquez Creus de La Vanguardia, por ejemplo), pero en general, el perfil del ponente en este congreso vasco suele ser más académico, es decir, profesores, tanto nacionales como extranjeros, que constituyen un referente en la investigación. El 80\% del comité científico del congreso está formado por profesores de la UPV, y el resto proceden de las universidades de Málaga, Santiago de Compostela, Navarra, Rovira y Virgili, Ramón Llul, Valencia y UCM. Los ponentes extranjeros suelen proceder de Brasil y Portugal. Los profesores invitados más habituales a este congreso son el prof. Javier Díaz Noci (Universidad Pompeu Fabra), el prof. Ramón Salaverría (Universidad de Navarra); y el profesor Xosé López (Universidad de Santiago de Compostela).

El Congreso de Periodismo en Red de Madrid se celebró en la Facultad de Ciencias de la Información de la Universidad Complutense, organizado por el profesor Jesús Flores durante cinco ediciones (2006-2010), reuniendo a los más prestigiosos profesionales y académicos del periodismo que analizaban los vertiginosos cambios de la información: desde las fuentes a los públicos, desde los medios tradicionales a 
las nuevas tecnologías digitales. El congreso nació en 2006 con el nombre de Congreso Internacional de Blogs y Periodismo en Red para quedarse, dos años después, en Congreso Internacional de Periodismo en Red.

Consolidó el concepto de Ciberperiodismo como causante de la "aldea global" de Marshall McLuhan y analizó la aparición de los nuevos medios, los cibermedios, donde el protagonista es el usuario como parte de una nueva audiencia: blogs, wikis y redes sociales que dan paso a un nuevo modelo informativo y de negocio que trae, por consiguiente, el estudio de un nuevo paradigma en el proceso de la comunicación. El congreso planteaba que, en la presente Sociedad del Conocimiento, el futuro de los medios de comunicación y el desarrollo del periodismo, implican, por un lado, nuevos planteamientos con profundos cambios en la formación de los profesionales $\mathrm{y}$, por otro, que los medios deben reconvertir y adaptar sus redacciones en unos modelos más flexibles para la producción de noticias. En este contexto, la idea del periodismo de hoy pasa porque sus profesionales conozcan el nuevo papel que les depara como intermediarios de información y gestores y organizadores del conocimiento, ya que cada vez más, vamos habituándonos a las nuevas formas de actuar e interactuar de la sociedad de la información.

Durante los dos primeros años, el congreso analizó la expansión y la consolidación de la blogosfera. En 2008, en la realización del III Congreso, el panel central se situó en torno a la explosión de la Web 2.0 y en 2009, en la IV edición, tuvo por eje central, los debates, análisis, reflexiones e investigaciones sobre nuevas formas del hacer periodístico, por lo que el tema central tuvo que ver con la Reinvención del Periodismo y los Medios.

En su última edición, en 2011, el V Congreso debatió la temática "Quinto Poder: Participación, Redes sociales y Cibermedios", tema central de gran interés -y también, preocupación- para los profesionales de la información, investigadores, estudiantes de periodismo y, sobre todo, para los propios medios de comunicación que sopesan la importancia de la información a través de los medios sociales. Además, se reflexionó sobre otros asuntos como el estado actual del periodismo, la expansión del fenómeno de las redes sociales, los nuevos perfiles profesionales, los blogs como modelos de negocio, la participación ciudadana en el nuevo entorno de la información, las tendencias del periodismo profesional, los nuevos géneros, la enseñanza-aprendizaje del periodismo y la comunicación en las facultades de Comunicación, etc.

Los objetivos del congreso eran ambiciosos porque trataban de buscar la doble perspectiva profesional-académica. Debatía y reflexionaba sobre la convergencia de los medios en la red, analizaba el fenómeno de las comunidades y consensuaba la experiencia profesional en los medios, atento siempre a los nuevos perfiles profesionales de Community Manager, Mobile Journalism e Influencer Blogger, entre otros. Desde su primera edición, el Congreso tuvo el objeto de constituirse en un foro de referencia obligada para docentes, investigadores, postgraduados, estudiantes y profesionales de la comunicación, interesados en el análisis, estudio e investigación de los procesos de información y comunicación en el nuevo contexto y marco tecnológico del Periodismo en la Red y su relación con los Nuevos Medios. 
Por último, en cuanto al Congreso de Periodismo y Comunicación Digital de Andalucía hay que señalar que nació durante la inauguración del Seminario de Periodismo Digital de Guadix, celebrado en marzo del 2006, a propuesta de la junta directiva de la Asociación de Periodistas Digitales de Andalucía (APDA), presidida entonces por Antonio Manfredi. Nacía con una periodicidad bienal, una duración de día y medio y ubicado en la sede de la Universidad Internacional de Andalucía en el monasterio de La Rábida (Huelva).

En 2013 celebró su IV edición, con más de un centenar de inscritos y se centró en dar voz a los profesionales del periodismo que encaraban la crisis de los medios con propuestas innovadoras y humildes. Supuso una vuelta a lo local, de contar en la red lo más cercano frente al exceso de información. Antonio Hernández Rodicio, director de la Cadena Ser en Andalucía fue la persona encargada de clausurar el última edición con un análisis del momento que atraviesa la profesión periodística castigada por la crisis e influida vertiginosamente por los cambios tecnológicos. El presidente de la APDA, Antonio Manfredi, también decano del Colegio Andaluz de Periodistas, hizo hincapié en la repercusión del evento en las redes sociales donde llegó a ser trending topic.

\section{El periodismo digital en el ámbito académico}

Atendiendo a la bibliografía consultada, se puede afirmar que una gran parte de los dedicados al ciberperiodismo trata de cómo escribir y publicar contenidos de calidad para la web, cómo actuar en la red y difundir materiales; herramientas 2.0 para plataformas periodísticas, etc. (Jaraba, 2014: 32). Los quince años del nuevo siglo han dado la perspectiva suficiente a algunos expertos para asegurar que la continuidad del periodismo, su futuro, está en la calidad y en la innovación.

Las tecnologías de la información se han convertido en herramientas inseparables de sociedad actual. Internet, los blogs, los medios sociales, la telefonía móvil y otras tecnologías emergentes han abierto un gran campo de acción en el entorno cambiante de los medios cada vez más creciente y busca ayudar a la creación, desarrollo y expansión de los nuevos medios. De ahí la gran importancia que encierra la investigación en materia del ciberperiodismo y los nuevos medios que permiten realizar una transferencia de conocimiento más eficaz y eficiente. Internet representa una nueva revolución en la forma de comunicación e información, razón por la cual, los medios de comunicación, escritos y audiovisuales, afectados por esta revolución informativa vienen transformando la actividad periodística de sus profesionales, proponiendo el uso de blogs y redes sociales en Internet (Flores, 2011: 178-179). El reto de los profesionales, emprendedores e invetigadores reunidos en torno a los congresos aquí analizados consiste en reinventar la forma y el contenido de la información periodística con el uso de Internet y sus aplicaciones.

Sobre la incidencia de la crisis en la situación laboral del periodista hay muestras más que suficientes. Desde lo local de los profesores Túñez y Sixto (2011), que analizan el sector audiovisual gallego, hasta el libro negro de la prensa o el último informe de la APM.

El conocimiento de las herramientas actuales es el primer reto para el profesional del periodismo y también para el futuro especialista de la información. El manejo de 
las herramientas disponibles, del software, bases de datos, búsqueda en la red, creación de sitios, tratamiento de imágenes, actualización y promoción; son aspectos básicos que hay que dominar. Muchas veces, ese desconocimiento ha hecho que no se use eficientemente al medio digital (Lerma Noriega, 2009: 376).

\section{Conclusiones}

Los congresos sobre periodismo digital que se celebran en España acostumbran a dejar muchas ideas y proyectos que intentan sortear la incertidumbre y la crisis del periodismo con la ayuda de las nuevas tecnologías. Como se ha recogido aquí, el más antiguo va por su XVI edición. Internet ya ha cumplido 30 años de vida, no parece tener mucho sentido seguir dando vueltas a la misma cuestión. La clave está en cómo volver a vivir del periodismo, digital en este caso, pero periodismo al fin y al cabo.

De las respuestas obtenidas a través de los cuestionarios a organizadores y ponentes de los congresos, se desprende que la nueva era apunta hacia la inestabilidad y el emprendimiento. Algunos de los ponentes consultados han pasado, en pocos años, por diferentes puestos laborales lo que indica la inestabilidad del empleo digital. El periodismo ha pasado a ser una vocación de la que ya muy pocos pueden comer. El modelo periodístico está en crisis... desde hace años. Se ha producido un divorcio entre el periodismo y los periodistas cansados del constante compromiso y del sacrificio que hoy en día exige la profesión. Es hora de avanzar, de arriesgar, de probar nuevos negocios. Los periodistas no son una especie a extinguir porque, sin su compromiso, la sociedad democrática corre peligro.

¿Son las empresas de medios las que han dado vuelta al negocio? ¿Han mercantilizado la información para ser empresas rentables? Casi todas las respuestas coinciden: el todo gratis parece no funcionar, se ha demostrado con creces. Hay que ser valientes y romper definitivamente con el modelo de negocio que nos está llevando a la ruina. Asumamos que pagar por lo contenidos no es un derecho, sino un deber que hay que ganarse. Y para eso, nada mejor que la calidad. Apostemos, pues, por la calidad. Es la única vía para reconciliar periodismo y periodistas. El negocio del periodismo ya no es lo que era, está experimentando, asumiendo riesgos, descubriendo nuevas sensaciones.

Todos los congresos analizados apuntaban en sus primeras ediciones a los blogs, como nueva forma y modelo de informar y comunicar empiezan a ganar cada vez más adeptos en el entorno de la información general y especializada, una tendencia que "tiene sus ventajas y desventajas, así como defensores y detractores quienes vienen debatiendo, analizando, y consensuando a través de foros nacionales e internacionales, el impacto que generan en la sociedad y en los medios (Cebrián y Flores, 2007: 16). Ya nadie duda del enorme impacto de las TIC en el corazón de los medios y el periodismo.

Las estructuras tradicionales han caído y se han originado nuevos modelos informativos convergentes en los que la propia concepción del periodismo se ha transformado.

Con el periodismo digital ¿han cambiado los contenidos? Los profesionales consultados considera que no y coinciden con la profesora Estrella Alonso, no (Alonso, 
2011: 108): "Los ciberperiódicos españoles de información general y de ámbito nacional no ofrecen aún auténticas noticias multimedia, sino recursos multimedia con los que complementar sus informaciones". Por lo tanto, cambia el tratamiento pero no los contenidos.

Parece claro que el futuro está en la red. Es más, ya no podríamos contemplar el panorama informativo sin ella, "pero todavía no está claro cómo hacer rentables las inversiones y, menos todavía, ganar dinero". (Navas, 2011: 25). Como en cualquier mercado emergente, hay mucha inestabilidad.

La batalla entre editores y los agregadores lleva años en la palestra. Es el caso de Google News, un agregador y buscador de noticias automatizado creado en 2002 que rastrea de forma constante la información de los principales medios de comunicación online. Desde su puesta en marcha, han sido numerosos los editores que demandan derechos de autor y reclaman a Google un pago por el uso de sus imágenes o noticias. Francia y Alemania han sido los pioneros (Calvo, 2014: 196). La batalla en España se ha saldado con la clausura, el martes 16 de diciembre de 2014, de Google News ante la Ley de Propiedad Intelectual. España se convierte así en el primer país del mundo en el que cierra este servicio ${ }^{1}$. No solo se cierra Google News. A partir ahora se han eliminado los contenidos de los medios españoles de todas las ediciones de este servicio en el mundo. El motivo del cierre es la negativa de Google a abonar la "compensación equitativa" que, con carácter irrenunciable, prevé la Ley de Propiedad Intelectual para los editores por el uso de sus noticias por parte de prestadores de servicios electrónicos de agregación.

La carencia de un negocio en la prensa digital ha provocado el incio de una etapa de experimentación y ensayo de nuevas estrategias y modelos de negocios (Goyanes Martínez, 2013: 427-428). La velocidad de Internet impide que grandes sectores e incluso, el académico, lleguen a asimilar con precisión el significado de los términos "estrategia" y "modelo de negocio" con la consiguiente confusión terminológica. Bajo esta perspectiva, Goyanes divide las estrategias de la prensa digital en propias (gratuitas, las más abundantes; o de pago (paywall) o en alianzas estratégicas, la mayoría de pago (propias (Orbyt) o ajenas (Kiosko y Más).

Las tecnologías no bastan para crear comunicación, afirma Dominique Wolton. El problema es que Internet, al ser abierta, se convierte en la gran tertulia global donde todos pueden participar. El periódico digital es un medio; la tecnología que utiliza, compartida por todos los usuarios, no lo es. Solo podemos aceptar como mass media escrito aquello que se ajusta a un proyecto y a un editor responsable que avala la profesionalidad de sus partícipes. Es un nuevo medio que utiliza la versatilidad de su soporte, la inmediatez que le proporciona y la posibilidad de integración de otros medios. Porque su mensaje no solo se sirve del texto, también de la imagen, cuenta con la reproducción de sonidos, con expresión oral y ofrece interacción. Esta complejidad de recursos define el neoperiodismo. Sus raíces son las del periodismo pero su proyección y polivalencia le configuran como realmente nuevo (Chivelet, 2011: 147-148).

${ }^{1} \mathrm{http}: / / \mathrm{www}$. abc.es/tecnologia/redes/20141216/abci-google-news-cierre-ley-propiedad-intelectual-201412151451.html [Consulta: 27 de enero de 2015] 
Las tendencias apuntan que los medios y los profesionales tienen solo dos caminos: reinventarse o morir. Sacudidas por el torbellino digital, las empresas periodísticas deben aferrarse a sus principales fortalezas que pasa por ser más pequeño y más móvil. Pero estas adaptaciones de nuevos medios no sólo afectan al medio sino también al mensaje, al canal, al receptor y al emisor. Los medios deben olvidarse de los soportes tradicionales y apostar por las nuevas vías que ofrecen las TIC. Los medios se trasladaron a la red, y de ahí a los dispositivos móviles. Quizá ahí esté el futuro (Cebrián y Flores, 2011: 216).

\section{Referencias bibliográficas}

ALONSO, Estrella (2011): "Los ciberperiódicos ¿hacen cibernoticias?", en VERÓN LASSA, José Juan y SABÉS TURMO, Fernando: La investigación en periodismo digital. Algunos trabajos desde el ámbito universitario. Huesca, Asociación de Periodistas de Aragón.

ALZAGA, Pedro (2011): La palabra escrita. Huesca, Asociación de Periodistas de Aragón.

CALVO, Elvira (2014): “Aspectos legales del periodismo en las redes sociales", en FLORES, Jesús (Coord.): Contenidos y servicios periodísticos en las redes sociales. Madrid, Editorial Fragua.

CEBRIÁN HERREOS, Mariano y FLORES VIVAR, Jesús (2011): Periodismo en la telefonía móvil. Madrid, Fragua.

CEBRIÁN, Mariano y FLORES, Jesús (2007): Blogs y periodismo en la red. Madrid, Fragua.

CHIVELET, Mercedes (2011): "Prensa de calidad y neoperiodismo digital", en FLORES, Jesús: Reiventar el periodismo y los medios. Apuntes sobre el estado del arte en la construcción del ciberperiodismo. Madrid, Fragua.

FLORES VIVAR, Jesús (2011): Reinventar el periodismo y los medios. Madrid, Fragua.

GOYANES MARTÍNEZ, Manuel (2013): "Estrategias y modelos de negocio: aclaración de conceptos y terminología de la prensa en Internet". Estudios sobre el Mensaje Periodístico, Volumen 19, núm. 1, pp. 419-431. Madrid, Servicio de Publicaciones de la Universidad Comlutense.

JARABA, Gabriel (2014): Periodismo en Internet: cómo escribir y publicar contenidos de calidad en la red. Madrid, Editorial Ma non troppo.

LERMA NORIEGA, Claudia Alicia (2009): "Una herramienta para el desarrollo del periodismo", en FLORES, Jesús y ESTEVE, Francisco (editores): Periodimos Web 2.0, Madrid, Fragua.

NAVAS GARCÍA, Alejandro (2011): 'La sociedad de la convergencia", en ALCUDIA BORREGUERO, Mario; LEGORBURU HORTELANO, José María; LÓPEZ DELGADO, Larissa; y RUIZ GÓMEZ, Sara. (coords.): Competidores y aliados. 
Medios en convergencia, los nuevos retos en comunicación, Madrid, CEU Ediciones.

TÚÑEZ, Miguel y SIXTO, José (2011): "Incidencia de la crisis en las condiciones laborales del periodismo audiovisual", en SIERRA, Javier; LIBERAL ORMAECHEA, Sheila; y CABEZUELO, Francisco (coords.): La Sociedad Digital. 113 propuestas de investigaciones en Comunicación, Madrid, CERSA. 